\title{
A Quantile Regression Analysis of Contributing Factors Influencing Agribusiness Growth and Entrepreneurship Development: Evidence from Rural China
}

\author{
Owusu Samuel Mensah ${ }^{1 \star}$ \\ Chen Jianlin ${ }^{2}$ \\ Ji You Jun ${ }^{3}$
}

${ }^{1,2, s}$ School of Business, Jinggangshan University, Qingyuan District, Ji'an City, Jiangxi Province, China Email:omensju15@yahoo.com

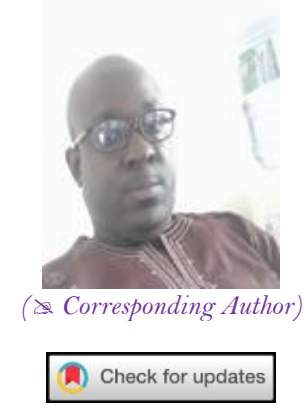

Abstract

The rapid development of some sectors in the Chinese economy has crippled the growth of agribusiness. Agribusiness sector, which consists of various business activities, plays a vital role in socio-economic development in the areas of job creation, food production and rural development. However, the environmental issues that are more prevalent to the agro-industries thwart the growth and development of the sector. This study employs the quantile regression approach to investigate the relationship between government policies, agribusiness growth and agripreneurship development. Pearson's product-moment correlation was also employed to investigate the degree of the linear relationship between the variables. The results of the study revealed a significant positive correlation between agribusiness development, rural education, Research and Development (R\&D), legalities, development of family households and intellectual properties. The quantile regression results also disclosed a positive relationship between investments in the rural areas and agribusiness growth and entrepreneurship development. The quantile plots measured the deviations in the asymmetric quantile coefficients, and the results revealed that the coefficients seem to depart slightly at the various quantile points, from the OLS mean effect estimates.

Keywords: Agribusiness growth, Entrepreneurship development, Government policies, Quantile regression and rural China. JEL Classification: H5 1; 128; J43; K49; L26; Q10; Q19.

\section{Introduction}

The role of agriculture in sustainable development and poverty reduction in most developing countries has become a major issue under discussion. The growth in the agricultural sector greatly contributes to Sustainable Development Goal of ending extreme poverty by 2030 and provides means to feed the expected nine billion people in the world by 2050 (Christiaensen et al., 2011). The future of agriculture has been intrinsically linked to the need for better stewardship of natural resources. In China, the agricultural sector serves as an important source of livelihood among many people in rural areas. For a sustainable and continual supply of food in China, the business ethics approach needs to be further encouraged in the agricultural production system among the rural dwellers. China, the country with the largest population worldwide and with arable land of 7 to 10 percent feeds the largest number of mouths in the world. However, the rapid population growth has called for an increase in the production and supply of food to meet the current and future food demand. Therefore, increasing food production means providing enabling environment to support the activities of the agricultural entrepreneurs and the agribusiness sector.

According to Edwards and Shultz "agribusiness is a dynamic and systemic endeavor that serves consumers globally and locally through innovations and management of multiple value chains that deliver valued goods and services derived from the sustainable orchestration of foods, fiber and natural resources"(Cristian and Felzensztein, 2013). The Oxford dictionary explains businesses as buying and selling or trade or commercial work. According to Acharya (2007) the word trade or commerce can be an exchange of goods as a means of livelihood or profit. That is agro-processing, production of agro-chemicals and farm machinery, and trade (wholesaling and retailing) are considered as parts of manufacturing (industrial) or service (tertiary) sector. With the structural transformation of the Chinese economy, there has been a decline in the share of agricultural production (farming), whilst the other sectors of the economy such as the processing, distribution and trade are increasingly developing.

Therefore, to address this issue, the agribusiness sector in China is adopting a more sustainable approach to ensure an increase in food production, effective and efficient food processing and distribution of agricultural products to make the sector more sustainable. Sustainable agriculture is perceived to be a philosophy and a system 
of farming because it is rooted in a set of values that reflects the awareness of both ecological and social realities (Altieri, 2018). Studies recognize agricultural systems as human systems, so that 'what is sustainable' will also be value-laden. The term agribusiness is generic and takes into consideration the involvement of the businesses in food production. According to Acharya (2007) agribusiness is about producing and adding value to the farm produce to meet the needs of customers. Agribusiness sector can be explained in four distinct sub-sectors, which are agricultural inputs; agricultural production; agro-processing; and marketing and trade (Acharya, 2007). Therefore, the concept "agribusiness" involves science and practice of activities, with backward and forward linkages, related to production, processing, marketing, trade, and distribution of raw and processed food, feed and fiber, including supply of inputs and services for these activities by the agri-food industries (Acharya, 2007).

The agri-food industry sector is a large, multifaceted industry sector that exists worldwide, and involves a range of businesses that create industry-specific. With increasingly competitive and quality conscious global marketplaces for food products, governments and agro-industry chain members are creating an enabling environment to promote food production. However, integrating the growing environmental and social issues of the changing agribusiness sector with prevailing economic imperatives is progressively becoming more difficult, however finding a lasting solution to these problems needs the involvement of agro-industries in the development of sustainable agricultural systems through the adoption of appropriate strategies. This will enhance a comprehensive conceptual framework and identify the most critical supportive policies, programs, and regulations needed to promote the agribusiness development. According to Kharaishvili et al. (2015) unfavorable business environment coupled with the introduction and adaptation of modern agricultural technology by agricultural entrepreneurs has been major obstacles facing the sector.

Agribusiness sector in China faces several challenges due to the market globalization, increased customer quality requirements in food products, changes in the market environment and the introduction and adoption of new technologies to enhance food production and supply. The adoption of the open market economy by the government has further resulted in growing competitive pressures among the agricultural clusters to improve farm revenue streams, development of new consumer market niches and creation of an enabling environment that supports the agri-food industries. According to Mintzberg (1996) the degree of stability or dynamism, simplicity or complexity, homogeneity or diversity, and munificence or hostility in the business environment play a significant role in developing the sector.

The external environment of the agro-industries is characterized by its narrow and broader senses, which focus on all the external objects and unequivocally affects the agro-industry performance. Hornsby et al. (2002) maintain that the interactions between forces in the external environment and the organization challenge firms to effectively sustain the business through appropriate business strategies. The concept of business environment talks about every variable, powers and the various institutions that have an immediate impact on the business activities.

The rest of the paper is structured as follows: Section 2 contains data and descriptive statistics; Section 3 explains the methods used in the analyses; Section 4 presents the results; Section 5 offers a discussion of the study's results, and Section 6 presents a brief conclusion.

\section{Materials and Methods}

\subsection{Measure}

In this paper, we adopted time series data and quantile regression model to investigate the contributing factors influencing agribusiness growth and agripreneurship development. The quantile regression approach helps to construct confident intervals for the fitted dependent variables. According to literature, common regression techniques focus on the mean effects, which may lead to either under-estimating or over-estimating the relevant coefficient or even failing to detect important relationships (Binder and Coad, 2011).

The study employed data from the China Statistical Yearbook, 2017. According to the study, the factors contributing to agribusiness development were measured using Household systems in the rural China (X 1), government expenditure on the rural education (X 2), patent grants (X 3), research and development (X4), tax incentives (X5), and the government expenditure in providing conducive legal environment to the entrepreneurs (X6).

The agribusiness performance (Y1) and the development of the agricultural entrepreneurs (Y2) were measured by and the total profit of agro-food industries and the number of agro-food industries from the period of 1978 to 2017 , respectively.

\subsection{Model Estimation}

The study, however, adopted a quantile regression approach introduced by Koenker and Bassett (1978) to find out the complex relationship between the dependent and independent variables. According to Uematsu et al. (2013) quantile regression is more robust to the non-normal error term and outliers in the model and takes into consideration the major effects of the covariates on the distribution of the dependent variable holistically and not only the conditional mean.

For a random variable $\mathrm{Y}$ with probability distribution function $G(y)=\operatorname{Pr} o b(Y \leq y)$,

the $\tau$ th quartile of $\mathrm{Y}^{*}$ is $\mathrm{d}$ the inverse function, $\beta(v)=\inf \{y: F(y) \geq v\}$

Where $0<v<1$. In particular, the median is $Q(1 / 2)$. The random sample $\left\{y_{1}, \ldots, y_{z}\right\}$ of $\mathrm{Y}$, means that the sample median minimizes the sum of absolute deviations $\min _{\alpha \in R} \sum_{i=1}^{M}\left|y_{i}-\chi\right|$. Likewise, the general $\tau$ th sample quantile $\chi(v)$, which is analogue of $\beta(v)$ is represented as $\min _{\alpha \in R} \sum_{i=1}^{M} \theta_{v}\left(y_{i}-\chi\right)$, where $\theta_{v}(k)=k(v-I(k<0)), 0<v<1$. Thus, 
$I($.$) represents the indicator function. However, Chen (2005)further states that likewise the sample mean, which$ tries to minimize the sum of the squared residuals $\hat{\sigma}=\arg \min _{\sigma \in} R \sum_{i=1}^{M}\left(y_{1}-\sigma\right)^{2}$. Can be extended to linear conditional mean function as $E(Y \mid X=x)=x^{\prime} \rho$ by solving $\hat{\rho}=\arg \min _{\rho \in} R^{H} \sum_{i=1}^{M} \beta v\left(y_{i}-x_{i}^{\prime} \rho\right)^{2}$ the linear conditional quantile function modeled as $\beta(v \mid X=x)=x^{\prime} \rho(v)$, is also estimated by solving $\hat{\rho}(v)=\arg \min _{\rho \in} R^{H} \sum_{i=1}^{M} \beta v\left(y_{i}-x_{i}^{\prime} \beta\right) \quad$ for any quantiles $v \in(0,1)$. The, quantity $\hat{\rho}(v)$ represents the $\tau$ th quantile regression. However, the $v=0.5$, relate to the median regression called the $L_{1}$ regression (Chen, 2005).

\section{Results and Discussion}

It is important to study the impact of Chinese government expenditure on the growth of the agribusiness sector and entrepreneurial development. The goodness-of-fit statistics for the quantile regression models are pseudo-R2 coefficients (based on the change in the deviance statistic). The study further runs a Pearson's productmoment correlation to assess the relationship between the agribusiness performance and government expenditure in education, patent, research institutions, tax incentives, legalities, and the family household system Table 1.

Table 2 shows the correlation between the agribusiness performance and government expenditure in education, patent, research institutions, tax incentives, legalities and the family household system. From Table 2 , there is a significant positive relationship between numbers of households in the rural areas and agribusiness growth in rural China, $\mathrm{r}=(22)=0.996, \mathrm{p}=0.000$. Moreover, the study revealed a significant positive relationship between investment in rural education and agribusiness growth. $r=(24)=0.971, p=0.000$. The findings further revealed a significant positive relationship between government expenditure in protecting the intellectual properties of the entrepreneurs $\mathrm{r}=(24)=0.822, \mathrm{p}=0.000$. The correlation between the government expenditure in promoting agricultural research and development and agribusiness growth was a significant positive relationship, $\mathrm{r}=(24)=0.671, \mathrm{p}=0.000$. The legal environment is also positively correlated with the agribusiness development at 0.001 significant level, $r=(24)=0.849, \mathrm{p}=0.001$. However, the tax incentives given to the agro-industries in the rural was positively correlated with the industrial growth in the rural areas but not significant, $r=(24)=0.239$, $\mathrm{p}=0.236$.

Table-1.Variables Definition and Summary Statistics.

\begin{tabular}{c|c|c|c|c}
\multicolumn{7}{c}{ Table-1.Variables Definition and Summary Statistics. } & Min. & Max. \\
\hline Variable & Mean & Std. Dev & & \\
\hline Dependent Variables & & & 10.055 & 12.551 \\
\hline $\mathrm{Y}_{1}$ & 10.826 & 10.189 & 10.298 & 11.481 \\
\hline $\mathrm{Y}_{2}$ & 11.124 & 10.351 & & 10.431 \\
\hline $\mathrm{X}_{1}$ & & & 9.110 & 7.324 \\
\hline $\mathrm{X}_{2}$ & 10.134 & 10.016 & 6.123 & 10.972 \\
\hline $\mathrm{X}_{3}$ & 9.085 & 11.232 & 7.251 & 9.137 \\
\hline $\mathrm{X}_{4}$ & 10.365 & 11.088 & 8.037 & 11.974 \\
\hline $\mathrm{X}_{5}$ & 8.085 & 10.214 & 9.321 & 12.431 \\
\hline $\mathrm{X}_{6}$ & 9.749 & 11.320 & 9.131 & \\
\hline Source: Authors' calculations based on data compiled from China Rural Statistical Yearbook $(1978-2017)$. & &
\end{tabular}

Table 3 and Table 4 report the standard errors of each regression coefficients estimated in the equation as well as the estimated results of the OLS method. According to the results from Table 3 and Table 4, most of the regression coefficients estimates are distinctly unequal to zero. Finally, the study estimated all the quantile regression estimated in the study. The estimated coefficients for the selected sample quantiles (20th, 40th, 60th and 80th), the standard errors, and confidence intervals for the quantile regression coefficient estimates are presented in Table 3 and Table 4.

In addition, apart from the quantile regression results at the various quantile points being different from the OLS estimation, the 20th, 40th, 60th and 80th quantiles estimations have a different significant effect on the conditional mean regression model. According to Karami and Mansoorabadi (2008) while the OLS regression describes the central tendency of the data, the regression quantile results give the exact picture of the importance of the explanatory variables for the different quantiles. This study, however, reports the statistical comparison coefficient, that is, testing the coefficients at the various quantile points and OLS estimate in Table 3 and Table 4. According to the study, the effect of the household system in rural China is lower in the OLS estimate and 80th quantile distribution. The mean effect of the family system is negatively significant according to the OLS estimate, but the quantile regression results show that the disparity is higher in the 20th, 40th, and 60th quantiles of the distribution. From Table 4, the mean effect of the family system is negative according to the OLS estimates and negatively significant in the 20th quantile point, but the quantile regression shows that the disparity is much higher in the upper quantiles of the distribution, such as the 40th, 60th and 80th quantiles at 0.05 significant levels. This implies that the family system in most of the rural areas in China is operating beyond subsistence farming by engaging in large scale farming, which generates income for the family. However, the results from Table 3 imply that the income from the sales of the farm produce is not enough to meet the needs of the farmers in most of the rural areas. 
Table-2.Pearson Product Moment Correlation.

\begin{tabular}{|c|c|c|c|c|c|c|c|}
\hline Variables & 1 & 2 & 3 & 4 & 5 & 6 & 7 \\
\hline \multirow[t]{2}{*}{ 1. $\mathrm{Y}_{1}$} & 1 & $0.996 * *$ & $0.971^{* *}$ & $0.822 * *$ & $0.671^{*} *$ & 0.239 & $0.849^{* *}$ \\
\hline & & 0.000 & 0.000 & 0.000 & 0.000 & 0.261 & 0.001 \\
\hline \multirow[t]{2}{*}{ 2. $\mathrm{X}_{1}$} & & 1 & $0.967 * *$ & $0.831 * *$ & $0.683^{*} *$ & 0.213 & $0.854 * *$ \\
\hline & & & 0.000 & 0.000 & 0.000 & 0.317 & 0.000 \\
\hline \multirow[t]{2}{*}{ 3. $\mathrm{X}_{2}$} & & & 1 & $0.930^{* *}$ & 0.817 ** & 0.015 & 0.939** \\
\hline & & & & 0.000 & 0.000 & 0.945 & 0.000 \\
\hline \multirow[t]{2}{*}{ 4. $\mathrm{X}_{3}$} & & & & 1 & $0.930 * *$ & 0.286 & $0.985^{* * *}$ \\
\hline & & & & & 0.00 & 0.186 & 0.00 \\
\hline \multirow[t]{2}{*}{ 5. $\mathrm{X}_{4}$} & & & & & 1 & $-0.545^{* *}$ & $0.930 * *$ \\
\hline & & & & & & 0.006 & 0.000 \\
\hline \multirow[t]{2}{*}{$6 . \mathrm{X}_{5}$} & & & & & & 1 & -0.255 \\
\hline & & & & & & & 0.229 \\
\hline 7. $\mathrm{X}_{6}$ & & & & & & & 1 \\
\hline
\end{tabular}

. Correlation is significant at the 0.01 level (2-tailed).

The study further looked at the influence of government expenditure on rural education on agribusiness growth and entrepreneurial development. From Table 3, the government commitment to equip the rural entrepreneurs with the requisite knowledge and skills recorded negatively on the agribusiness growth at the OLS estimate, 20th and 40th quantile points. However, across all the quantile points the effects were highly significant at $5 \%$ and $10 \%$ level and the effect of rural education on agribusiness growth in the upper tail of the distribution was positive. According to Table 4, the impact of public investment in rural education on the empowerment of entrepreneurship among the rural farmers was positive in the OLS estimate and positively significant in the 20th and 80th quantile points.

Table-3.OLS and quantileregression coefficients for covariates of agribusiness performance $\left(\mathrm{Y}_{1}\right)$.

\begin{tabular}{|c|c|c|c|c|c|}
\hline Variables(No.) & OLS & 0.20 & 0.40 & 0.60 & 0.80 \\
\hline $\mathrm{X}_{1}$ & $\begin{array}{c}-1.2006^{* * *} \\
(0.203)\end{array}$ & $\begin{array}{c}3.879 * * \\
(0.103)\end{array}$ & $\begin{array}{c}2.108 * * * \\
(0.331)\end{array}$ & $\begin{array}{l}1.043^{*} \\
(0.187)\end{array}$ & $\begin{array}{l}-0.576 \\
(0.059)\end{array}$ \\
\hline $\mathrm{X}_{2}$ & $\begin{array}{r}-0.0651 \\
(0.268) \\
\end{array}$ & $\begin{array}{c}-1.581^{* * *} \\
(0.036)\end{array}$ & $\begin{array}{c}-0.325^{*} \\
(0.197)\end{array}$ & $\begin{array}{c}0.257 * * \\
(0.137) \\
\end{array}$ & $\begin{array}{l}0.159^{*} \\
(0.212) \\
\end{array}$ \\
\hline $\mathrm{X}_{3}$ & $\begin{array}{c}0.0143^{* *} \\
(0.043) \\
\end{array}$ & $\begin{array}{l}0.043^{*} \\
(1.137) \\
\end{array}$ & $\begin{array}{c}0.061 \\
(0.158)\end{array}$ & $\begin{array}{c}0.154 * * * \\
(0.191) \\
\end{array}$ & $\begin{array}{c}0.412^{* *} \\
(0.267)\end{array}$ \\
\hline $\mathrm{X}_{4}$ & $\begin{array}{l}0.0142 \\
(0.006) \\
\end{array}$ & $\begin{array}{l}-1.424 \\
(0.198)\end{array}$ & $\begin{array}{c}0.195^{* *} \\
(0.110)\end{array}$ & $\begin{array}{c}0.0597^{*} \\
(0.290)\end{array}$ & $\begin{array}{c}0.019 \\
(0.099) \\
\end{array}$ \\
\hline $\mathrm{X}_{5}$ & $\begin{array}{c}0.219 \\
(0.002)\end{array}$ & $\begin{array}{l}-0.024 \\
(0.225)\end{array}$ & $\begin{array}{c}0.002 * * \\
(0.197)\end{array}$ & $\begin{array}{c}0.161 \\
(0.145)\end{array}$ & $\begin{array}{c}-0.061 * * \\
(0.083)\end{array}$ \\
\hline $\mathrm{X}_{6}$ & $\begin{array}{c}0.294^{* *} * \\
(0.003)\end{array}$ & $\begin{array}{c}0.2795^{*} \\
(0.225)\end{array}$ & $\begin{array}{l}-0.006 \\
(0.198) \\
\end{array}$ & $\begin{array}{c}-1.417^{*} \\
(0.277)\end{array}$ & $\begin{array}{c}-1.025^{* *} \\
(0.330) \\
\end{array}$ \\
\hline $\begin{array}{c}\mathrm{R}^{2} \\
\text { Pseudo }\end{array}$ & 0.9925 & 0.9335 & 0.8923 & 0.9406 & 0.930 \\
\hline
\end{tabular}

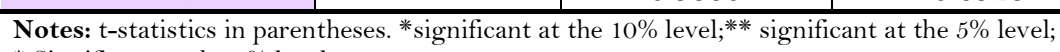

* Significant at the $1 \%$ level.

Getting government support in the area of patent application plays a major role in protecting investment and promoting innovative ideas among entrepreneurs. Therefore, the study investigated how to patent right leads to agribusiness growth and entrepreneurial development in rural China.

The results from Table 3 show that the effect of government support in granting and protecting the patent right is superior to that of agricultural entrepreneurs in rural areas. The mean effect of the patent is about 0.01 according to the OLS estimate. However, the quantile regression reveals that the disparity is much smaller in the lower quantiles of the distribution and higher in the upper quantiles of the distribution at $0.01,0.05$ and 0.1 significant level.

The study further examined the contribution of investment in research and development $(\mathrm{R} \& \mathrm{D})$ in improving agribusiness performance and entrepreneurial development. From Table 3, the effect of the research and development $(\mathrm{R} \& \mathrm{D})$ on agribusiness development is positively significant for the 40th and 80th tails of the distribution and recorded positively insignificant at the 60th quantile.

However, at the lowest (20th) quantile, the results showed that the coefficient of the R\&D negatively affected the agribusiness growth during the study period. From Table 4, the contribution of R\&D in developing the farmer entrepreneur reaches $5 \%$ and $10 \%$ significant levels at 0.40 and 0.60 quantile regression models. This revealed that $\mathrm{R} \& \mathrm{D}$ does not completely contribute to entrepreneurial development in most of the rural areas in China. This result matches the result from Table 4, which revealed that patent application and patent right failed to contribute positively and significantly to entrepreneurial development at the 40th and 80th quantile distributions. 
Table-4.OLS and quantile regression coefficients for covariates of Entrepreneurship Development $\left(\mathrm{Y}_{2}\right)$.

\begin{tabular}{|c|c|c|c|c|c|}
\hline Variables(profit) & OLS & 0.20 & 0.40 & 0.60 & 0.80 \\
\hline $\mathrm{X}_{1}$ & $\begin{array}{l}-0.246 \\
(0.022) \\
\end{array}$ & $\begin{array}{c}-0.139^{*} \\
(0.244)\end{array}$ & $\begin{array}{c}0.0443 * * \\
(0.385) \\
\end{array}$ & $\begin{array}{c}0.910^{* * *} \\
(0.381)\end{array}$ & $\begin{array}{c}1.492^{* * *} * \\
(0.680)\end{array}$ \\
\hline $\mathrm{X}_{2}$ & $\begin{array}{c}0.307 \\
(0.159)\end{array}$ & $\begin{array}{l}1.176^{*} \\
(0.729)\end{array}$ & $\begin{array}{c}-0.0948 \\
(0.755) \\
\end{array}$ & $\begin{array}{c}-0.1016^{* *} \\
(0.529) \\
\end{array}$ & $\begin{array}{c}0.1022^{*} \\
(0.855)\end{array}$ \\
\hline $\mathrm{X}_{3}$ & $\begin{array}{c}0.2972^{* *} \\
(0.002) \\
\end{array}$ & $\begin{array}{l}0.625^{*} \\
(0.085) \\
\end{array}$ & $\begin{array}{c}-0.1016 \\
(0.563) \\
\end{array}$ & $\begin{array}{c}0.0122^{*} * \\
(0.944) \\
\end{array}$ & $\begin{array}{r}-0.0540 \\
(0.785) \\
\end{array}$ \\
\hline $\mathrm{X}_{4}$ & $\begin{array}{l}0.0231 \\
(0.052) \\
\end{array}$ & $\begin{array}{r}-0.1120 \\
(0.138) \\
\end{array}$ & $\begin{array}{c}0.0482^{* *} \\
(0.164) \\
\end{array}$ & $\begin{array}{c}0.0803^{*} \\
(0.075)\end{array}$ & $\begin{array}{c}0.397 \\
(0.183) \\
\end{array}$ \\
\hline $\mathrm{X}_{5}$ & $\begin{array}{l}0.009^{*} \\
(0.126) \\
\end{array}$ & $\begin{array}{c}-0.0944 \\
(0.692) \\
\end{array}$ & $\begin{array}{c}-0.0232 * * \\
(0.836) \\
\end{array}$ & $\begin{array}{c}-0.1084 \\
(0.414) \\
\end{array}$ & $\begin{array}{l}0.005^{*} \\
(0.840) \\
\end{array}$ \\
\hline $\mathrm{X}_{6}$ & $\begin{array}{c}0.054^{* *} \\
(0.321) \\
\end{array}$ & $\begin{array}{l}0.054^{*} \\
(0.122) \\
\end{array}$ & $\begin{array}{c}0.0387^{*} * \\
(0.005) \\
\end{array}$ & $\begin{array}{c}0.0201 * \\
(0.053)\end{array}$ & $\begin{array}{c}0.1040^{*} \\
(0.227) \\
\end{array}$ \\
\hline $\begin{array}{c}\mathbf{R}^{2} \\
\text { Pseudo }\end{array}$ & 0.9807 & 0.9260 & 0.9064 & 0.9013 & 0.9016 \\
\hline
\end{tabular}

* significant at the $1 \%$ level.

In the case of tax incentives, the OLS estimate indicated a positive relationship between tax incentives given to agro-industries and agribusiness growth; however the quantile regression showed negatively significant effect only at the 80th quantile. From Table 4, the effect of the tax incentives given to the agricultural entrepreneurs is positively significant at both the OLS estimates and the higher (80th) quantile distribution. However, at the lower and middle quantiles (20th, 40th and 60th) of the distribution, the coefficients showed a negative impact on the entrepreneurial development. This may suggest that government grants to farmers and agro-industries in the rural areas are not appropriately and evenly distributed, therefore, it is advisable for the central government to increase the incentives given to the small businesses and redefine "small business", more especially in the rural areas.

Providing an effective legal environment for businesses to operate according to the study promote SMEs' growth and development. The legal support given to the agro-industries by the central government in most of the rural areas is statistically significant at the OLS estimate and the lower quantile point, however, the coefficients at the higher (60th and 80th) quantiles of the distribution was statistically insignificant. Contrary to the results from Table 3, the legal support was found to be statistically significant in developing the agricultural entrepreneurs in rural areas across the OLS estimate and the quantile points, Table 4. The study, therefore, suggests the introduction of Small Business Legal assistance programs to provide legal information to small business owners and prospective agricultural entrepreneurs who operate in low-income communities.

The graphical representations of the estimates for all the quantiles are given in Figure 1 and Figure 2. The shaded area gives confidence band of coefficients estimated across different quantiles. From Figure 1, the effect of the family system on the agribusiness development recorded positively at the lower tails of the distribution as compared to the higher quantiles of the distribution. From Figure 2, the effect on entrepreneurial development was positive at the higher quantile point and by examining the pattern of the plot presented in Figure 1 and Figure 2 at the higher quantile (80th). Moreover, a similar pattern is observed for the variable research and development. According to the results, the coefficient changes over the range of about -1.4 to approximately 0.1 for the quantile varies between 0.2 and 0.8., Figure 1. As reported in Figure 1, the influence of tax incentive is negative at the lower quantile point but different at the upper quantile of the distribution. From Figure 2, the influence of the tax incentive on the entrepreneurship development is higher at the 80th quantile of the distribution. In addition, the influence of the legal environment on agribusiness growth above the higher quantile is stronger as compared to entrepreneurship development. The quantile plots revealed deviations in the asymmetric quantile coefficients and departs slightly at the various quantile points and from the OLS estimates. Figure 1 and Figure 2 show a series of plots whereby the OLS mean effect and the 80 percent confidence interval is compared with the regression quantile effects and the 80 percent confidence intervals. The plots clearly reveal how the OLS estimates represent the conditional distribution of agribusiness performance, quantitatively and qualitatively. The graphs further revealed striking differences between OLS and quantile results.
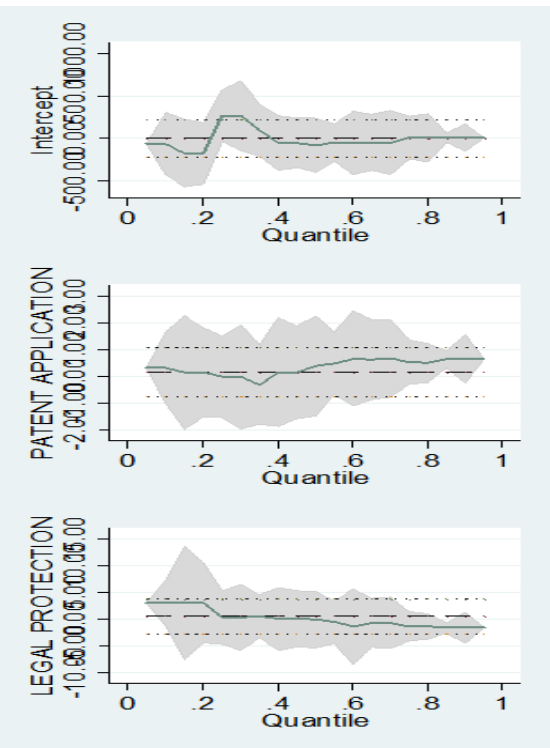
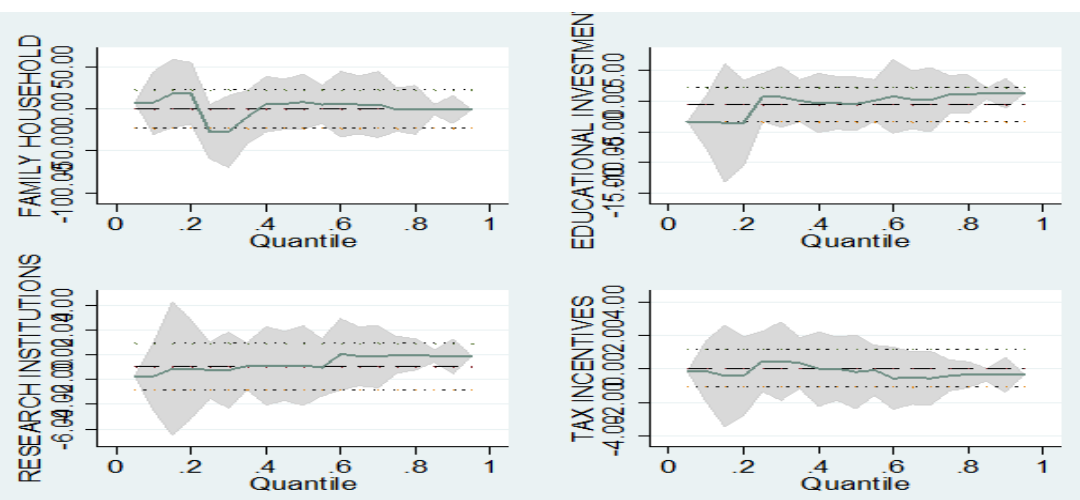

Figure-1.Graphical representation of the regression estimates (Agribusiness Growth). 

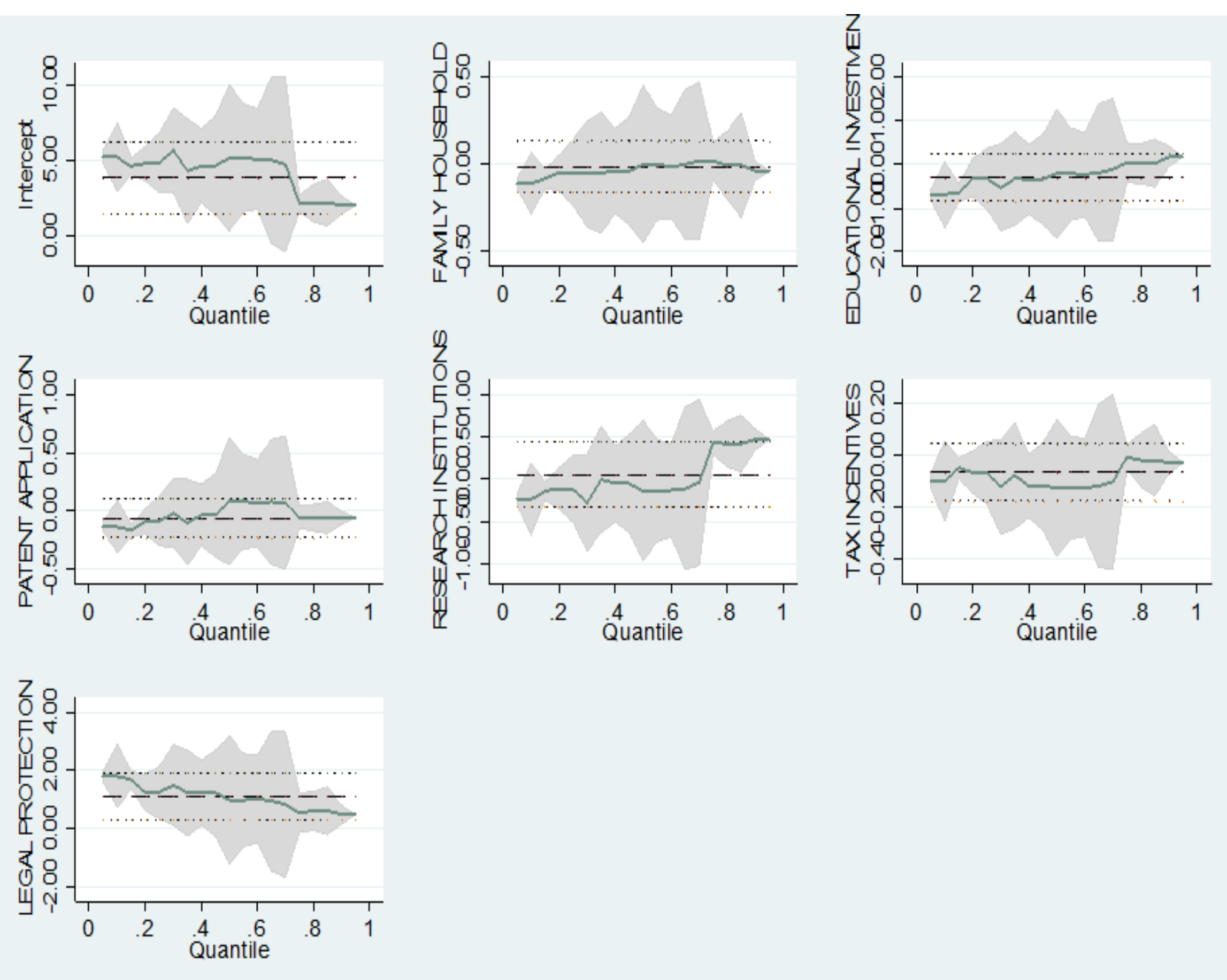

Figure-2. Graphical representation of the regression estimates (Entrepreneurship Development).

\section{Conclusion}

The paper primarily sought to determine the factors promoting agribusiness growth and entrepreneurial development in rural China. Times series data from China Statistical Yearbook from 1978 to 2017 were selected for the study, and further employed quantile regression approach, which is more robust to the non-normal error term and outliers in the model and takes into consideration the major effects of the covariates on the distribution of the dependent variable holistically and not only the conditional mean.

The results of the study revealed a positive effect of the family system on agribusiness performance at the quantile distributions. This implies that favorable institutional policies by the central government have some level of impact on the growth of the agribusiness sector and development of agricultural entrepreneurs in rural China. Moreover, investment in education, which equips the human capital with knowledge and skills, plays a major role in promoting agribusiness sector.

Therefore, investment in rural education, which is a major human capital tool, is necessary for the development of agricultural entrepreneurs. The contributing effect of patents rights and patent application to agribusiness are significantly positive on agribusiness development.

The results from the study imply that the ability of firms to cope with technological changes play a critical role in developing the agricultural entrepreneurs and the agribusiness sector. Concerning legal issues, the results indicate that building vibrant and favorable legal business environment for businesses to operate boost the confidence level of the local entrepreneurs, which has a consequential effect on business performance. However, the effect of the policy environment on the firm's performance differs slightly, despite the strong effect on agroindustry performance at various quantile points. The coefficient of legal support in the 20th quantile is almost the same as that compare to the OLS estimate in Table 3.

The study, however, suggests that for development of agribusiness in rural areas, most of the rural policies should be focusing on equipping the rural farmers to develop entrepreneurial skills and development to see their farms as a business.

\section{References}

Acharya, S.S., 2007. Agribusiness in India: Some facts and emerging issues. Agricultural Economics Research Review, 20(1): 409-424

Altieri, M.A., 2018. Agroecology: The science of sustainable agriculture. CRC Press.

Binder, M. and A. Coad, 2011. From average Joe's happiness to Miserable Jane and Cheerful John: Using quantile regressions to analyze the full subjective well-being distribution. Journal of Economic Behavior \& Organization, 79(3): 275-290.Available at: https://doi.org/10.1016/j.jebo.2011.02.005.

Chen, C., 2005. An introduction to quantile regression and the QUANTREG procedure. Paper Presented at the Proceedings of the Thirtieth Annual SAS Users Group International Conference.

Christiaensen, L., L. Demery and J. Kuhl, 2011. The (evolving) role of agriculture in poverty reduction-an empirical perspective. Journal of Development Economics, 96(2): 239-254.Available at: https://doi.org/10.1016/j.jdeveco.2010.10.006.

Cristian, G. and C. Felzensztein, 2013. Marketing innovations in the agribusiness sector. Academia Latin American Administration Academy, 26(1): 108-138.Available at: https://doi.org/10.1108/arla-05-2013-0042.

Hornsby, J.S., D.F. Kuratko and S.A. Zahra, 2002. Middle managers' perception of the internal environment for corporate entrepreneurship: Assessing a measurement scale. Journal of Business Venturing, 17(3): 253-273.Available at: https://doi.org/10.1016/s08839026(00)00059-8. 
Karami, E. and A. Mansoorabadi, 2008. Sustainable agricultural attitudes and behaviors: A gender analysis of Iranian farmers. Environment, Development and Sustainability, 10(6): 883-898.Available at: https://doi.org/10.1007/s 10668-007-9090-7.

Kharaishvili, E., G. Erkomaishvili and M. Chavleishvili, 2015. Problems faced by the agricultural sector and agribusiness development strategy in Georgia. World Academy of Science, Engineering and Technology, International Journal of Social, Behavioral, Educational, Economic, Business and Industrial Engineering, 9(11): 3833-3837.

Koenker, R. and J.G. Bassett, 1978. Regression quantiles. Econometrica, 46(1): 33-50.Available at: https://doi.org/10.2307/1913643.

Mintzberg, H., 1996. Managing government, governing management. Harvard Business Review, 74(3): 75.

Uematsu, H., A.R. Khanal and A.K. Mishra, 2013. The impact of natural amenity on farmland values: A quantile regression approach. Land Use Policy, 33: 151-160.Available at: https://doi.org/10.1016/j.landusepol.2012.12.007.

Citation | Owusu Samuel Mensah; Chen Jianlin; Ji You Jun (2019). A Quantile Regression Analysis of Contributing Factors Influencing Agribusiness Growth and Entrepreneurship Development: Evidence from Rural China. Asian Business Research Journal, 4: 10-16.

History:

Received: 10 January 2019

Revised: 18 February 2019

Accepted: 22 March 2019

Published: 15 May 2019

Licensed: This work is licensed under a Creative Commons

Attribution 3.0 License (cc) Er

Publisher: Eastern Centre of Science and Education
Acknowledgement: All authors contributed to the conception and design of the study.

Funding: This study is funded by National Self-finance Fund Project "Based on the Dual Network Embedding of Small and Micro Enterprises' Life Cycle Trap Breakthrough Mechanism and Path Research" with Item Number: Trap Breakthrough Mechanism and Path Research" with Item Number:
7156302 .

Competing Interests: The authors declare that they have no conflict of interests.

Transparency: The authors confirm that the manuscript is an honest, accurate, and transparent account of the study was reported; that no vital features of the study have been omitted; and that any discrepancies from the features of the study have been omitted
study as planned have been explained.

Ethical: This study follows all ethical practices during writing.

Eastern Centre of Science and Education is not responsible or answerable for any loss, damage or liability, etc. caused in relation to/arising out of the use of the content. Any queries should be directed to the corresponding author of the article. 